\title{
Childhood bullying victimization is associated with use of mental health services over five decades: a longitudinal nationally representative cohort study
}

\author{
S. Evans-Lacko ${ }^{1,2 *}$, R. Takizawa ${ }^{3,4}$, N. Brimblecombe ${ }^{1}$, D. King ${ }^{1}$, M. Knapp ${ }^{1}$, B. Maughan ${ }^{4}$ and \\ L. Arseneault ${ }^{4}$ \\ ${ }^{1}$ Personal Social Services Research Unit, London School of Economics and Political Science, Houghton Street, London WC2A 2AE, UK \\ ${ }^{2}$ Health Service and Population Research Department, Institute of Psychiatry, Psychology \& Neuroscience, King's College London, De Crespigny \\ Park, London SE5 8AF, UK \\ ${ }^{3}$ Department of Neuropsychiatry, Graduate School of Medicine, The University of Tokyo, 7-3-1, Hongo, Bunkyo-ku, Tokyo 113-8655, Japan \\ ${ }^{4}$ SGDP Research Centre, Institute of Psychiatry, Psychology \& Neuroscience, King's College London, De Crespigny Park, London SE5 8AF, UK
}

Background. Research supports robust associations between childhood bullying victimization and mental health problems in childhood/adolescence and emerging evidence shows that the impact can persist into adulthood. We examined the impact of bullying victimization on mental health service use from childhood to midlife.

\begin{abstract}
Method. We performed secondary analysis using the National Child Development Study, the 1958 British Birth Cohort Study. We conducted analyses on 9242 participants with complete data on childhood bullying victimization and service use at midlife. We used multivariable logistic regression models to examine associations between childhood bullying victimization and mental health service use at the ages of 16, 23, 33, 42 and 50 years. We estimated incidence and persistence of mental health service use over time to the age of 50 years.

Results. Compared with participants who were not bullied in childhood, those who were frequently bullied were more likely to use mental health services in childhood and adolescence [odds ratio (OR) $2.53,95 \%$ confidence interval (CI) 1.88-3.40] and also in midlife (OR 1.30, 95\% CI 1.10-1.55). Disparity in service use associated with childhood bullying victimization was accounted for by both incident service use through to age 33 years by a subgroup of participants, and by persistent use up to midlife.

Conclusions. Childhood bullying victimization adds to the pressure on an already stretched health care system. Policy and practice efforts providing support for victims of bullying could help contain public sector costs. Given constrained budgets and the long-term mental health impact on victims of bullying, early prevention strategies could be effective at limiting both individual distress and later costs.
\end{abstract}

Received 19 January 2016; Revised 20 June 2016; Accepted 21 June 2016; First published online 28 September 2016

Key words: Adolescents, bullying, children, health service, mental health.

\section{Introduction}

Early adverse experiences can increase vulnerabilities to mental health problems across the life course (Shonkoff et al. 2009); in turn, these may have implications for mental health service use. Childhood bullying victimization is one such adverse experience and is increasingly recognized as a public health concern (Gilbert et al. 2009). Empirical evidence supports strong and robust associations with mental health symptoms in childhood and adolescence (Arseneault et al. 2010). Studies have also shown that childhood bullying

* Address for correspondence: S. Evans-Lacko, Ph.D., Personal Social Services Research Unit, London School of Economics and Political Science, Houghton Street, London WC2A 2AE, UK.

(Email: s.evans-lacko@lse.ac.uk) victimization is associated with persisting problems in early adulthood (Copeland et al. 2013) and even up to midlife (Takizawa et al. 2014). We hypothesized that bullying victimization might have an effect on mental health service use, not only during childhood and adolescence, but also across the life course.

Some evidence indeed points in that direction. A registry-based study of a nationwide Finnish birth cohort indicated that childhood bullying victimization was associated with greater use of psychotropic medication and psychiatric hospitalizations during early adulthood, over and above psychopathology prior to bullying (Sourander et al. 2009, 2016). This is important as it also indicates that early childhood bullying victimization can have important implications for healthcare systems. At this stage, however, little is known about broader patterns of mental health-related service 
use, and whether such an impact is persistent over time. We examine the impact of childhood bullying victimization on mental health service use in childhood and adolescence, early adulthood, and up to midlife in a nationally representative UK birth cohort followed to the age of 50 years. To further contextualize our results, we compare the association between childhood bullying victimization and ever being 'in care' on mental health service use, as being in care is a known marker of later mental health problems (Odgers \& Jaffee, 2013).

\section{Method}

\section{Participants}

Data came from the National Child Development Study (NCDS), the 1958 British Birth Cohort Study (Power \& Elliott, 2006). Information was collected on $98 \%$ of all births in 1 week in 1958 in England, Scotland and Wales (17638 participants). Subsequent follow-ups took place at ages 7 (1965), 11 (1969) and 16 years (1974) in childhood, and at ages 23 (1981), 33 (1991), 42 (2000), 45 (2003) and 50 years (2008) in adult life. During the childhood surveys the sample was augmented by 920 immigrants to the UK who were born in the study week, for a total of 18558 cohort members.

\section{Measures}

\section{Assessment of bullying}

Exposure to bullying was assessed via parental interviews when participants were aged 7 and 11 years. At each age, parents were asked if their child was bullied by other children never, sometimes or frequently. We combined responses from both interviews $(n=11$ 872 ) to create a three-level indicator of exposure to childhood bullying: $0=$ never bullied (never at both 7 and 11 years); $1=$ occasionally bullied (sometimes at either 7 or 11 years); 2 = frequently bullied (frequently at either 7 or 11 years, or sometimes at both ages). Where only one parental interview was available $(n=2511$ at age 7 years, $n=1563$ at age 11 years), responses from that interview were used, providing bullying assessments for $86 \%$ of cohort members.

\section{Mental health service use}

The NCDS collects data on use of health services in relation to a range of medical conditions. For this study, we focused on health service use reported specifically in relation to mental health problems. The exact questions about mental health service use, the providers involved and the time-frames covered are presented in online Supplementary Appendix S1. Reports of service use in childhood and adolescence (from ages 11 to
16 years) were recorded in the course of an examination by a local authority medical officer, who consulted available records and interviewed the young people and their parents. Cohort members' own reports of adult service use related to the intervals between adult survey sweeps, which varied between 1 and 10 years. This allowed for assessment of the impact of bullying in relation to a range of services and settings at different life stages. Because absolute rates of reported service use inevitably vary for different providers (e.g. general practitioners $v$. specialist mental health professionals) and for different observation periods, we focused predominantly on the ratios between groups according to bullying victimization rather than absolute rates of service use.

\section{Childhood sociodemographic and clinical characteristics}

Childhood intelligence quotient (IQ) was assessed at age 11 years using a standardized 80 -item general ability test (Douglas, 1964). Scales of childhood emotional and behavioural problems were derived from teacher ratings on the Bristol Social Adjustment Guides (Stott, 1969) (precursors to more recent behaviour ratings) at ages 7 and 11 years. These scales show adequate reliability, and predict psychiatric morbidity in adult life (Clark et al. 2007). We used the mean of scores across the ages of 7 and 11 years where both measures were available $(n=12781)$, and single-age measures for the remainder of the sample $(n=3522)$. Family social class in childhood was classified on the basis of the father's occupation at age 7 years, and categorized as 'I and II' (professional/managerial/technical), 'IIINM' (other non-manual), 'IIIM' (skilled manual) and 'IV and V' (unskilled manual) (Office of Population Censuses and Surveys, 1980). Childhood adversity was assessed from both prospective and retrospective reports. Prospectively, parents/caretakers reported at the age-11 years contact whether the child had ever been in the care of a local authority or voluntary agency. In addition, information collected from parents and teachers was used to create an eight-item scale of low parental involvement, including indicators of the child's physical appearance and the parents' activities with the child at the ages of 7 and 11 years (Power et al. 2012). Parents and caretakers reported at the age-11 years contact whether the child had ever been in the care of the local authority or a voluntary agency. Retrospectively at age 45 years, participants completed a 16-item questionnaire about their exposure to a range of childhood adversities including poverty, parental mental health and drug/alcohol problems, family conflict, and physical and sexual abuse (Rosenman \& Rodgers, 2004). We grouped responses into those reporting no $(47 \%)$, one $(25 \%)$ and two or more adversities (28\%). 


\section{Statistical analysis}

First, we calculated the frequency of mental health service use by childhood bullying victimization, overall and by gender for each assessment. Next, five separate multivariable logistic regression models examined the impact of childhood bullying victimization on mental health service use at each interview time point. Each multivariable model adjusted for all confounders described previously. As it was not possible to directly compare the absolute prevalence estimates of service use over time given the differences in how questions were asked at each survey year, we compared the odds ratio (OR) associated with service use for those who were frequently bullied $v$. never and occasionally bullied $v$. never bullied. To provide an estimate of the magnitude of the association between bullying and mental health service use, in a separate model, we investigated the link between ever being 'in care' and mental health service use.

Second, we examined patterns of mental health service use over time and whether the same group of individuals accounted for the majority of service use across age, or whether different individuals were using services at each time point. For this analysis, we assessed (i) incidence of mental health service use at each time point (i.e. new 'cases' who had not reported any previous mental health service use), and (ii) the persistence of mental health service use across time (by adding together the number of reported service use contacts from childhood through to age 50 years).

All statistical models built on the analyses from our past research which investigated midlife mental health outcomes of childhood bullying victimization (Takizawa et al. 2014), and included the same covariates. The analyses incorporated inverse probability weights to address sample attrition; these were derived from logistic regression analyses predicting availability of complete data on childhood bullying and service use at age 50 years. As a conservative approach, we report on individuals who had complete data on bullying in childhood and service use at age 50 years $(n=$ 9242). Sensitivity analysis did not identify differences in mental health service use between those with and without complete data. As participants were based across the UK, we examined whether region of residence was related to use of mental health services. As no significant association was identified, we did not include this variable in our subsequent analyses. Analyses were carried out using SAS version 9.3 (USA) and Stata version 11.2 (USA).

\section{Ethical standards}

All procedures contributing to this work comply with the ethical standards of the relevant national and institutional committees on human experimentation and with the Helsinki Declaration of 1975, as revised in 2008 .

\section{Results}

Frequency of mental health service use over the lifespan by bullying victimization

The prevalence of mental health service use for individuals who were frequently or occasionally bullied in childhood was greater than for those who were not bullied (Table 1). This trend was evident when looking at general, specialty and child and adolescent mental health service use. However, even those who were occasionally bullied in childhood had greater use of mental health services compared with those who were not bullied (except for specialist out-patient and in-patient services at age 16 years and mental health specialty service use at age 33 years). The associations between bullying victimization and service use were characterized by an age-related gradient: we observed greater disparity in service use associated with bullying victimization at younger ages compared with later, when individuals were farther away from the exposure of interest. Except for age 16 years, there was no difference in service use between those who were occasionally $v$. frequently bullied. Rates of service use varied by gender, with females having higher rates of mental health service use in adulthood and males having higher rates of service use in childhood and adolescence. Prevalence of service use according to bullying victimization is presented separately for males and females and the associations between bullying and service use were consistent within each gender (Table 1).

\section{Longitudinal trends of mental health service use according to bullying victimization}

Bullying victimization was associated with mental health service use from age 16 up to age 50 years (Table 2): participants who were bullied, either occasionally or frequently, had a higher risk of using mental health services up to midlife compared with those who were not bullied. Fig. 1 also illustrates that the disparity between those participants who had been bullied or not in childhood was greatest at age 16 years, suggesting that the impact of bullying victimization on mental health service use was most pronounced at the time point closest to the exposure, and particularly for those who were frequently bullied. The higher risk of use of mental health services for individuals who were occasionally or frequently bullied in childhood decreased with age, but remained significant up to the age of 50 years. This association was also robust to controls for the potentially confounding effects of 


\begin{tabular}{|c|c|c|c|c|c|c|c|c|c|c|}
\hline \multirow{3}{*}{$\begin{array}{l}\text { Age at } \\
\text { interview, } \\
\text { years }\end{array}$} & \multirow[b]{3}{*}{ Service type } & \multicolumn{9}{|c|}{ Bullied at age 7 or 11 years, $\%$ (95\% confidence interval) } \\
\hline & & \multicolumn{3}{|l|}{ Total sample } & \multicolumn{3}{|l|}{ Male } & \multicolumn{3}{|l|}{ Female } \\
\hline & & Never bullied & $\begin{array}{l}\text { Occasionally } \\
\text { bullied }\end{array}$ & $\begin{array}{l}\text { Frequently } \\
\text { bullied }\end{array}$ & Never bullied & $\begin{array}{l}\text { Occasionally } \\
\text { bullied }\end{array}$ & $\begin{array}{l}\text { Frequently } \\
\text { bullied }\end{array}$ & Never bullied & $\begin{array}{l}\text { Occasionally } \\
\text { bullied }\end{array}$ & $\begin{array}{l}\text { Frequently } \\
\text { bullied }\end{array}$ \\
\hline \multirow[t]{4}{*}{16} & $\begin{array}{l}\text { Specialist out- } \\
\text { patient }\end{array}$ & $2.0(1.5-2.5)$ & $3.1(2.2-3.9)$ & $5.9(4.2-7.5)$ & $2.7(1.9-3.6)$ & $3.6(2.3-4.9)$ & $7.0(4.6-9.4)$ & $1.3(0.8-1.8)$ & $2.4(1.4-3.6)$ & $4.2(2.2-6.3)$ \\
\hline & $\begin{array}{l}\text { Specialist } \\
\text { in-patient }\end{array}$ & $1.1(0.7-1.3)$ & $1.6(1.0-2.2)$ & $2.2(1.3-3.2)$ & $1.3(0.7-2.9)$ & $1.5(0.7-2.3)$ & $2.7(1.2-4.2)$ & $0.8(0.4-1.2)$ & $1.7(0.8-2.6)$ & $1.5(0.2-2.7)$ \\
\hline & Primary care & $1.2(0.8-1.6)$ & $3.3(2.4-4.3)$ & $4.0(2.6-5.3)$ & $1.7(1.0-2.4)$ & $4.5(3.0-6.1)$ & $4.7(2.7-6.8)$ & $0.7(0.3-1.1)$ & $2.0(1.0-3.0)$ & $2.9(1.2-4.6)$ \\
\hline & Specialist any & $3.7(3.1-4.4)$ & $6.5(5.3-7.8)$ & $11.0(8.8-13.1)$ & $4.9(3.8-6.0)$ & $8.2(6.2-10.1)$ & $13.1(9.9-16.2)$ & $2.6(1.8-3.3)$ & $4.7(3.2-6.2)$ & $8.0(5.2-10.7)$ \\
\hline 23 & Specialist & $2.7(2.2-3.2)$ & $4.1(3.2-5.0)$ & $4.4(3.2-5.6)$ & $1.2(0.7-1.7)$ & $2.9(1.8-3.9)$ & $2.9(1.5-4.3)$ & $4.1(3.2-4.9)$ & $5.5(4.1-7.0)$ & $6.3(4.1-8.5)$ \\
\hline \multirow[t]{2}{*}{33} & Primary care & $19.2(18.0-20.4)$ & $23.1(21.3-25.0)$ & $23.3(20.7-25.9)$ & $11.7(10.3-13.2)$ & $13.8(11.7-16.0)$ & $15.5(12.5-18.5)$ & $26.3(24.5-28.1)$ & $33.4(30.5-36.4)$ & $33.5(29.2-37.8)$ \\
\hline & Specialist & $7.6(6.8-8.1)$ & $9.2(7.9-10.4)$ & $9.9(8.1-11.7)$ & $5.6(4.6-6.7)$ & $6.1(4.6-7.6)$ & $7.0(4.9-9.2)$ & $9.5(8.2-10.7)$ & $12.6(10.5-14.7)$ & $13.6(10.5-16.8)$ \\
\hline 42 & $\begin{array}{l}\text { Primary care/ } \\
\text { specialist }\end{array}$ & $3.9(3.3-4.4)$ & $5.8(4.7-6.8)$ & $5.7(4.4-6.8)$ & $2.8(2.1-3.5)$ & $5.0(3.7-6.4)$ & $4.0(3.5-6.4)$ & $4.8(3.9-5.7)$ & $6.6(5.0-8.1)$ & $5.8(3.8-7.8)$ \\
\hline 50 & $\begin{array}{l}\text { Primary care/ } \\
\text { specialist }\end{array}$ & $12.3(11.3-13.2)$ & $15.1(13.5-16.6)$ & $15.8(13.7-17.9)$ & $8.6(7.5-9.7)$ & $9.4(7.8-11.0)$ & $10.8(8.5-13.1)$ & $15.2(13.9-16.5)$ & $19.6(17.4-21.8)$ & $20.9(17.6-24.3)$ \\
\hline
\end{tabular}




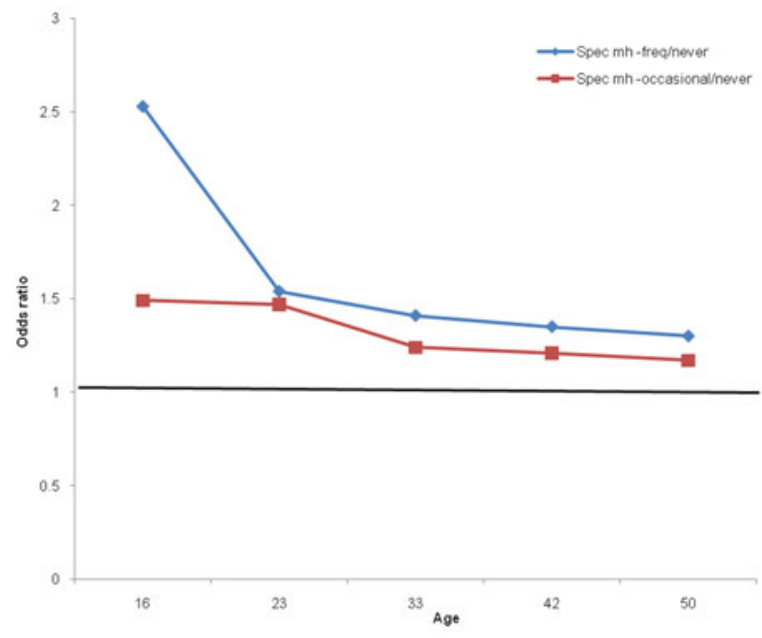

Fig. 1. Odds ratio of the prevalence of specialty mental health (spec $\mathrm{mh}$ ) service use for individuals who were frequently $v$. never bullied (freq/never) and occasionally $v$. never bullied (occasional/never).

childhood IQ, socio-economic status of parents, low parental involvement, childhood emotional and behavioural problems, and childhood adversity (see online Supplementary Appendix S2 for details of the full model and adjusted OR for each covariate). Reassuringly, associations between covariates and service use identified here were similar to those found in the broader mental health literature in that females and those who experienced childhood adversity were more likely to use mental health services.

To provide an estimate of the magnitude of the association between bullying and mental health service use, in a separate model, we investigated the link between ever being 'in care' and mental health service use. The odds of mental health service use at age 50 years for individuals who were in care in childhood [OR 1.40, 95\% confidence interval (CI) 1.02-1.94] were significantly greater than for individuals who had not been in care, but not significantly different in magnitude than for those who were bullied either occasionally or frequently (for example, frequently bullied $v$. not bullied: OR 1.30, 95\% CI 1.10-1.55).

\section{Incidence and persistence of mental health service use over the lifespan}

The persisting association between bullying victimization and mental health service use was not simply due to the same individuals using mental health services over time (Fig. 2); we observed new cases of mental health service use after childhood. There was a disparity in mental health service use at age 16 years according to bullying victimization, when the risk is greatest, but also at the ages of 23 and 33 years. By age 42 years, 


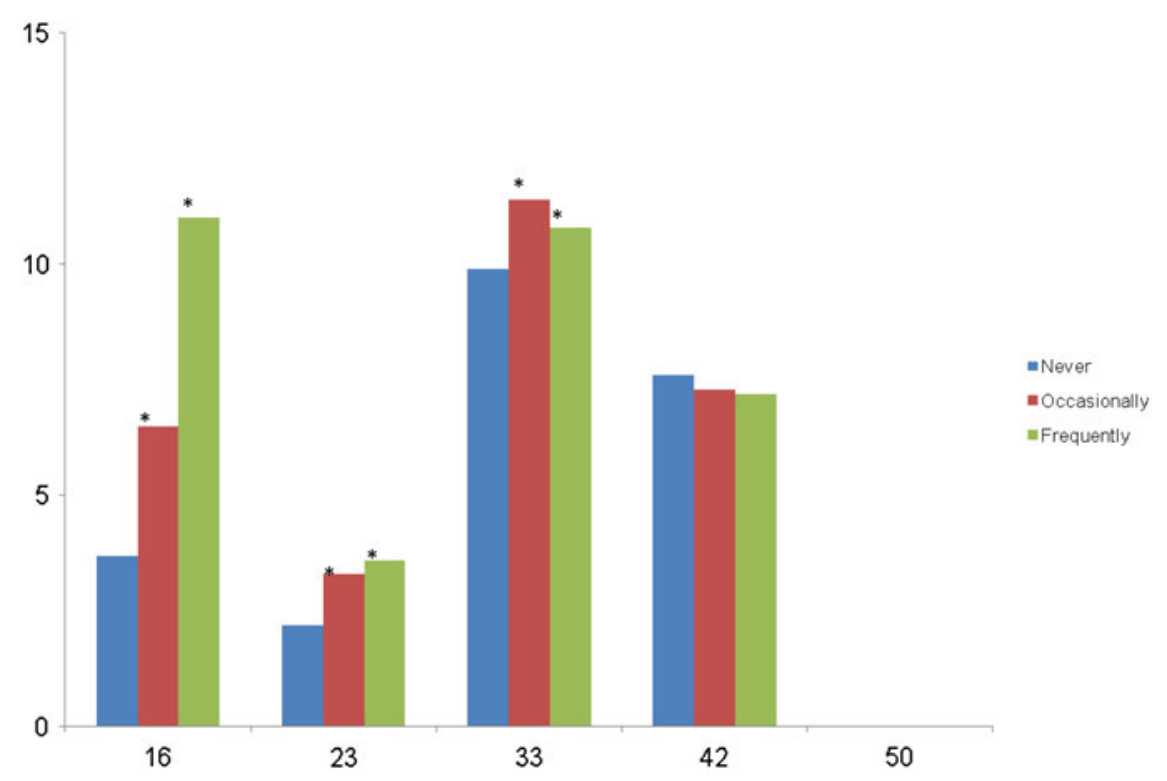

Fig. 2. Incidence of service use (\%) over time by bullying victimization; where we have more than one measure of service use (ages 16 and 33 years), we included the measure indicating specialty mental health service use. ${ }^{*}$ Statistical significance $(p<$ 0.05), relative to never bullied.

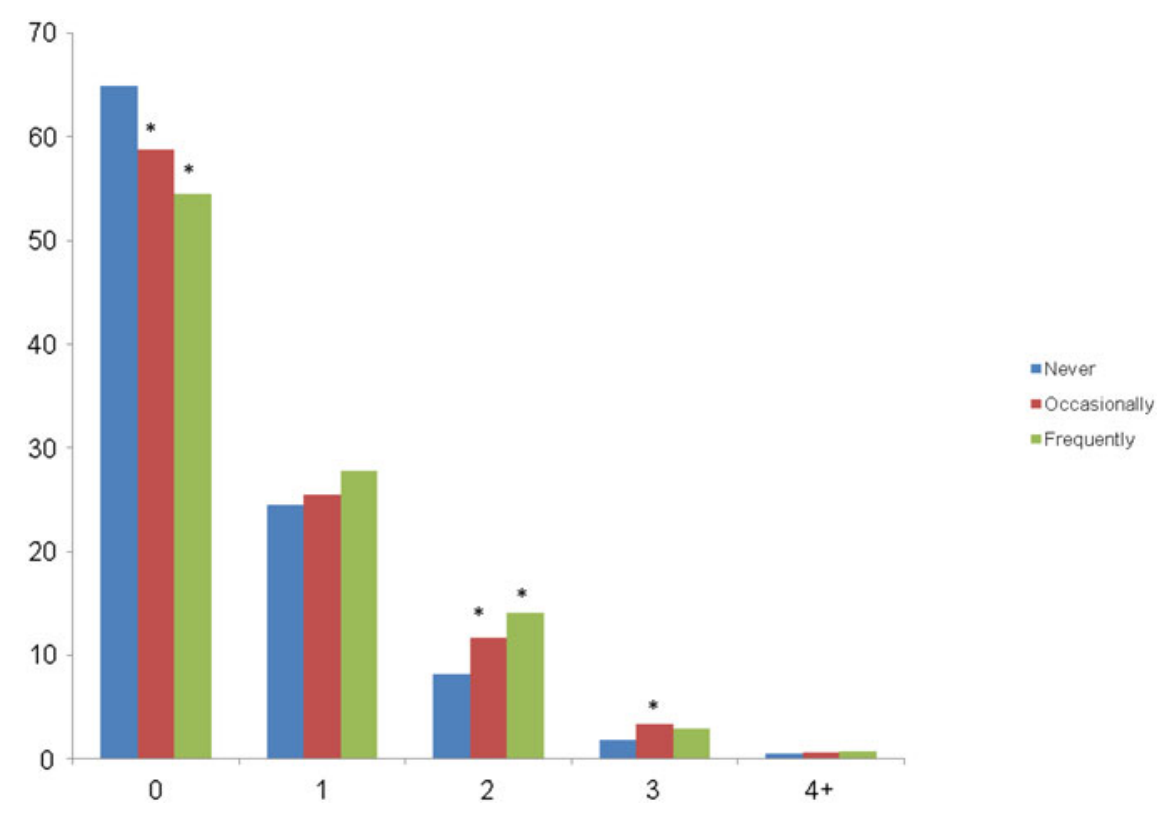

Fig. 3. Persistence (\%) of mental health service use encounters $(0,1,2,3$ or $4+)$ over the lifespan by bullying victimization. * Statistical significance $(p<0.05)$, relative to never bullied.

there were no differences in incidence of service use by bullying victimization and no new mental health service use was reported at age 50 years. Individuals who were occasionally or frequently bullied also showed more persistent service use over time than those who were not bullied, as indicated by the total number of reported mental health service use encounters across assessment periods (Fig. 3).

\section{Discussion}

Being bullied in childhood has previously been shown to be associated with poor mental health up to midlife. In this study, using a large prospective British birth cohort, we show that childhood bullying victimization is also associated with a long-term impact on mental health service use through to midlife. This has 
important implications for an already stretched healthcare system, given the durability of the impact we identified over time. The impact on mental health services is most notable at an early age, as would perhaps be expected, but the association remains significant at age 50 years, despite controlling for established correlates of bullying victimization and mental health problems. Increased service use among those who experienced childhood bullying victimization resulted from individuals with early-onset mental health problems who continued to use services over their lifetime, in addition to some new cases who started using mental health services in their 20s and 30s. As a result, our study suggests that, in addition to reducing suffering, actions to prevent bullying in childhood and adolescence could reduce some of the pressures on healthcare resources.

The persistence of the association between childhood bullying victimization and mental health service use across nearly four decades, although diminishing over time, is surprising and deserves further attention. This long-term effect might reflect at least two different processes. First, half of the adult population with a psychiatric disorder already show signs of poor mental health by the age of 15 years (Kim-Cohen et al. 2003). If unnoticed or untreated, early onset of mental health problems could be the starting point of persistent disorders, especially those childhood and adolescent mental health problems known to be associated with bullying victimization, including depression and anxiety (Arseneault et al. 2008; Bowes et al. 2014), self-harm (Fisher et al. 2012; Lereya et al. 2013), suicidality (Geoffroy et al. 2016), and psychotic disorders (Arseneault et al. 2011; van Dam et al. 2012). Second, bullying victimization may set the conditions for a cycle in which people become at risk of exposure to further abuse in later life (Dodge et al. 1990). The cumulative effect of being repeatedly exposed to victimization - and its detrimental effect on wellbeing - may push some individuals to seek help for mental health problems only when they transition to early adulthood. This pathway may also be exacerbated by the poor social outcomes associated with childhood bullying victimization, such as marital failure and poor employment outcomes (Goodman et al. 2011; Knapp et al. 2011).

Overall, we did not find that bullying victimization increased mental health service use more specifically for boys or girls. However, we observed that boys showed higher levels of mental health service use at age 16 years compared with girls. This difference probably reflects the key role that adults play in recognizing, referring and engaging with mental health services and the higher rates of externalizing symptoms among young boys (Costello et al. 1998; Stiffman et al. 2004), whereas, later on, men seek care on their own behalf.
In agreement with previous research, our study also indicates higher rates of mental health service use among females compared with males in adulthood. This may be due to stigma associated with mental health problems among men or their inability to recognize feelings of distress and seek help (Wang et al. 2007; Mojtabai, 2010; Evans-Lacko et al. 2014).

\section{Limitations}

This study was based on a large nationally representative cohort with data from face-to-face interviews with participants and their families across five decades. The impact of childhood bullying victimization on mental health service use at midlife was robust to controls for a number of factors we know to be associated with mental health problems, and is consistent with our previous studies showing an association with mental and physical health problems despite considering the confounding effects of several key variables. Nevertheless, the study has a number of limitations. First, attrition is notable over the 50-year assessment period. It is unlikely that this affected our findings; however; we showed previously that dropout was unrelated to bullying victimization (Takizawa et al. 2014) and other observable attributes (Hawkes \& Plewis, 2006). Furthermore, we controlled for other effects of selective attrition by including inverse probability weights throughout the analyses. Second, the service use measures may be vulnerable to recall bias. Although it was not possible to verify interview reports of service use with medical records, past research has shown good agreement between selfreports and hospital and emergency service use over the lifetime (Horwitz et al. 2001). Reliability of reports of out-patient visits is lower; however, moderate to high agreement has been shown for reports of outpatient visits over a 1-year period (Horwitz et al. 2001), and self-report is considered an acceptable method for collecting service use data (Patel et al. 2005). Third, interview questions about service use varied across assessments (i.e. at different ages), rendering direct comparisons of utilization over time difficult. Nevertheless, the assessment of a variety of types of mental health service use at different ages allowed us to validate the impact of bullying victimization across mental health service settings and life stages. Service use for drug and alcohol problems, however, was only covered up to age 42 and not at age 50 years. Fourth, and by the same token, our assessment of service use was not comprehensive and most probably did not capture all types of mental health service use - although we report on the most common ones. Moreover, we did not have data on the intensity of mental health service use. Finally, although participants were representative of UK 
births in 1958, the cohort lacks the ethnic diversity currently found in the UK (Power \& Elliott, 2006) and may not accurately represent patterns of service use today.

Bullying is widespread among primary and secondary school students (Gilbert et al. 2009; Finkelhor et al. 2015). Attention to this issue has been growing in policy and related discussions; for example, bullying was referred to 72 times in the Chief Medical Officer's report for 2013, highlighting it as an issue of particular importance and in need of expert attention (Davies \& Mehta, 2014). Our study showed that childhood bullying victimization adds to the pressure on a healthcare system which is already stretched, as bullying victimization was associated with long-term effects on service use through to age 50 years. Anti-bullying initiatives are relatively inexpensive and offer good value for money (Beecham et al. 2011). One model developed for the National Institute for Clinical Excellence estimated that a school-based anti-bullying initiative costs around $£ 15.50$ per pupil, per year (Hummel et al. 2009). Given the tremendous current strain on the healthcare system, specific policy and practice efforts to prevent bullying could not only reduce individual suffering over many years, but also help to contain or even reduce costs.

\section{Supplementary material}

The supplementary material for this article can be found at http://dx.doi.org/10.1017/S0033291716001719

\section{Acknowledgements}

There was no funder which specifically supported this paper, although N.B.'s time was funded from a National Institute for Health Research Senior Investigator award to M.K.; R.T. is a Newton International Fellow Alumnus funded by the Royal Society, the British Academy and through a Grant-inAid for Scientific Research (B) (JSPS KAKENHI Grant Number JP16H05653) from the Japanese Society for the Promotion of Science (JSPS); S.E.-L. currently holds a Starting Grant from the European Research Council (337673). The authors had final responsibility for the decision to submit for publication. The funders played no part in the design or conduct of the study, the analysis or interpretation of data, or the writing of the article and the decision to submit it for publication.

\section{Declaration of Interest}

None.

\section{References}

Arseneault L, Bowes L, Shakoor S (2010). Bullying victimization in youths and mental health problems: 'much ado about nothing'? Psychological Medicine 40, 717-729.
Arseneault L, Cannon M, Fisher HF, Polanczyk G, Moffitt TE, Caspi A (2011). Childhood trauma and children's emerging psychotic symptoms: a genetically sensitive longitudinal cohort study. American Journal of Psychiatry 168, 65-72.

Arseneault L, Milne BJ, Taylor A, Adams F, Delgado K, Caspi A, Moffitt TE (2008). Being bullied as an environmentally mediated contributing factor to children's internalizing problems: a study of twins discordant for victimization. Archives of Pediatrics and Adolescent Medicine 162, 145-150.

Beecham J, Byford S, Kwok C, Parsonage M (2011). School-based interventions to reduce bullying. In Mental Health Promotion and Mental Illness Prevention: the Economic Case (ed. M. Knapp, D. McDaid and M. Parsonage), pp. 12-13. Department of Health: London.

Bowes L, Wolke D, Joinson C, Lereya ST, Lewis G (2014). Sibling bullying and risk of depression, anxiety, and self-harm: a prospective cohort study. Pediatrics 134, e1032e1039.

Clark C, Rodgers B, Caldwell T, Stansfeld S (2007). Childhood and adulthood psychological ill health as predictors of midlife affective and anxiety disorders: the 1958 British Birth Cohort. Archives of General Psychiatry 64, 668-678.

Copeland WE, Wolke D, Angold A, Costello EJ (2013). Adult psychiatric outcomes of bullying and being bullied by peers in childhood and adolescence. JAMA Psychiatry 70, 419-426.

Costello EJ, Pescosolido BA, Angold A, Burns B (1998). A family network-based model of access to child mental health services. Research in Community Mental Health 9, 165-190.

Davies S, Mehta N (2014). Public Mental Health: Evidence Based Priorities. The Annual Report of the Chief Medical Officer 2013: Public Mental Health Priorities: Investing in the Evidence. Department of Health: London.

Dodge K, Bates J, Pettit G (1990). Mechanisms in the cycle of violence. Science 250, 1678-1683.

Douglas JWB (1964). The Home and the School. MacGibbon \& Kee: London.

Evans-Lacko S, Corker E, Williams P, Henderson C, Thornicroft G (2014). Trends in mental illness related public stigma among the English population in 2003-2013: influence of the Time to Change anti-stigma campaign. Lancet Psychiatry 1, 121-128.

Finkelhor D, Turner HA, Shattuck A, Hamby SL (2015). Prevalence of childhood exposure to violence, crime, and abuse: results from the National Survey of Children's Exposure to Violence. JAMA Pediatrics 169, 746-754.

Fisher HL, Moffitt TE, Houts RM, Belsky DW, Arseneault L, Caspi A (2012). Bullying victimisation and risk of self harm in early adolescence: longitudinal cohort study. BMJ (Clinical Research ed.) 344, e2683.

Geoffroy MC, Boivin M, Arseneault L, Turecki G, Vitaro F, Brendgen M, Renaud J, Séguin JR, Tremblay RE, Côté SM (2016). Associations between peer victimization and suicidal ideation and suicide attempt during adolescence: results from a prospective population-based 
birth cohort. Journal of the American Academy of Child and Adolescent Psychiatry 55, 99-105.

Gilbert R, Widom CS, Browne K, Fergusson D, Webb E, Janson S (2009). Burden and consequences of child maltreatment in high-income countries. Lancet 373, 68-81.

Goodman A, Joyce R, Smith JP (2011). The long shadow cast by childhood physical and mental problems on adult life. Proceedings of the National Academy of Sciences of the United States of America 108, 6032-6037.

Hawkes D, Plewis I (2006). Modelling non-response in the National Child Development Study. Journal of the Royal Statistical Society, Series A 169, 479-491.

Horwitz S, Hoagwood K, Stiffman AR, Summerfeld T, Weisz JR, Costello EJ, Rost K, Bean DL, Cottler L, Leaf PJ, Roper M, Norquist G (2001). Reliability of the services assessment for children and adolescents. Psychiatric Services (Washington, D.C.) 52, 1088-1094.

Hummel S, Naylor P, Chilcott J, Guillaume L, Wilkinson A, Blank L, Baxter S, Goyder E (2009). Cost-effectiveness of Universal Interventions Which Aim to Promote Emotional and Social Wellbeing in Secondary Schools. University of Sheffield: Sheffield.

Kim-Cohen J, Caspi A, Moffitt TE, Harrington H, Milne BJ, Poulton R (2003). Prior juvenile diagnoses in adults with mental disorder: developmental follow-back of a prospective-longitudinal cohort. Archives of General Psychiatry 60, 709-717.

Knapp M, King D, Healey A, Thomas C (2011). Economic outcomes in adulthood and their associations with antisocial conduct, attention deficit and anxiety problems in childhood. Journal of Mental Health Policy and Economics 14, 137-147.

Lereya ST, Winsper C, Heron J, Lewis G, Gunnell D, Fisher HL, Wolke D (2013). Being bullied during childhood and the prospective pathways to self-harm in late adolescence. Journal of the American Academy of Child and Adolescent Psychiatry 52, 608-618.e2.

Mojtabai R (2010). Mental illness stigma and willingness to seek mental health care in the European Union. Social Psychiatry and Psychiatric Epidemiology 45, 705-712.

Odgers CL, Jaffee SR (2013). Routine versus catastrophic influences on the developing child. Annual Review of Public Health 34, 29-48.

Office of Population Censuses and Surveys (OPCS) (1980). Classification of Occupations. HMSO: London.

Patel A, Rendu A, Moran P, Leese M, Mann A, Knapp M (2005). A comparison of two methods of collecting economic data in primary care. Family Practice 22, 323-327.
Power C, Elliott J (2006). Cohort profile: 1958 British birth cohort (National Child Development Study). International Journal of Epidemiology 35, 34-41.

Power C, Thomas C, Li L, Hertzman C (2012). Childhood psychosocial adversity and adult cortisol patterns. British Journal of Psychiatry: the Journal of Mental Science 201, 199-206.

Rosenman S, Rodgers B (2004). Childhood adversity in an Australian population. Social Psychiatry and Psychiatric Epidemiology 39, 695-702.

Shonkoff JP, Boyce WT, McEwen BS (2009). Neuroscience, molecular biology, and the childhood roots of health disparities: building a new framework for health promotion and disease prevention. JAMA 301, 2252-2259.

Sourander A, Gyllenberg D, Brunstein Klomek A, Sillanmäki L, Ilola AM, Kumpulainen K (2016). Association of bullying behavior at 8 years of age and use of specialized services for psychiatric disorders by 29 years of age. JAMA Psychiatry 73, 159-165.

Sourander A, Ronning J, Brunstein Klomek A, Gyllenberg D, Kumpulainen K, Niemelä S, Helenius H, Sillanmäki L, Ristkari T, Tamminen T, Moilanen I, Piha J, Almqvist F (2009). Childhood bullying behavior and later psychiatric hospital and psychopharmacologic treatment: findings from the Finnish 1981 Birth Cohort Study. Archives of General Psychiatry 66, 1005-1012.

Stiffman AR, Pescosolido B, Cabassa LJ (2004). Building a model to understand youth service access: the gateway provider model. Mental Health Services Research 6, 189-198.

Stott DH (1969). The Social Adjustment of Children. University of London Press: London.

Takizawa R, Maughan B, Arseneault L (2014). Adult health outcomes of childhood bullying victimization: evidence from a five-decade longitudinal British birth cohort. American Journal of Psychiatry 171, 777-784.

van Dam DS, van der Ven E, Velfhorst E, Selten JP, Morgan C, de Haan L (2012). Childhood bullying and the association with psychosis in non-clinical and clinical samples: a review and meta-analysis. Psychological Medicine 42, 2463-2474.

Wang PS, Aguilar-Gaxiola S, Alonso J, Angermeyer MC, Borges G, Bromet EJ, Bruffaerts R, de Girolamo G, de Graaf R, Gureje O, Haro JM, Karam EG, Kessler RC, Kovess V, Lane MC, Lee S, Levinson D, Ono $Y$, Petukhova M, Posada-Villa J, Seedat S, Wells JE (2007). Use of mental health services for anxiety, mood, and substance disorders in 17 countries in the WHO World Mental Health Surveys. Lancet 370, 841-850. 